\title{
STRATEGI LIRANG DALAM PENENTUAN HARGA JUAL PISANG DI PASAR TRADISIONAL BLITAR
}

\author{
Endah Masrunik ${ }^{1}$, Bambang Septiawan ${ }^{2}$, Anditya Dian Hendriawan ${ }^{3}$ \\ Fakultas Ekonomi Universitas Islam Balitar

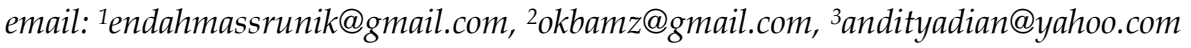

\section{Kata kunci:}

Strategi Lirang

Kulitatif

Harga Jual

Pisang

Keywords:

Lirang Strategy

Qualitative

Selling Price

Banana

\section{Endah Masrunik, Bambang Septiawan dan Andity Dian Hendriawan.(2019).Strategi Lirang Dalam Penentuan Harga Jual Pisang Di Pasar Tradisional Blitar. Akuntabilitas: Jurnal Ilmiah Ilmu- Ilmu Ekonomi,12 (2), 97-105.}

\begin{abstract}
ABSTRAK
Penelitian ini bertujuan untuk mengetahui bagaimana strategi dalam penentuan harga jual buah pisang yang digunakan oleh pedagang buah pisang di Pasar tradisional Blitar. Penelitian ini menggunakan metode penelitian kualitatif dengan pendekatkan studi fenomenologi yaitu dengan melakukan wawancara yang mendalam dan pengamatan terkait tingkah laku maupn sikap para pedagang dalam melakukan suatu transaksi jual beli. Hasil penelitian ini, menunjukan bahwa pedagang menentukan harga jual buah pisang berdasarkan lirang, dimana pisang dalam satu thandan akan di bagi menjadi beberapa lirang. Kemudian akan dilihat jenisnya, ukuran, jumlah buah pisang dalam satu lirang, tingkat kematangan, dan kondisi pasar saat itu. Penentuan harga jual berdasarkan lirang ini dinilai pedagang lebih mudah penerapannya, karena pedagang tidak perlu menimbang buah pisang yang dijualnya dan strategi atau cara ini sudah sejak dulu digunakan oleh pedagang buah pisang di pasar tradisional.
\end{abstract}

\section{ABSTRACT}

This study focuses to determine how the strategy in determining the selling price of bananas applied by banana traders in Blitar traditional markets. This study uses a qualitative research method with the approach of study phenomenology, by conducting in-depth interviews and observations related to the behavior and attitudes of traders in making a sale and purchase transaction. The results of this study shows that traders determine the selling price of bananas based on the lirang strategy, while in one part and will be divided into several lirang. Then it will see the type, size, a number of bananas in one lirang, level of ripe, and current market conditions. Determination of selling prices based on this lirang is considered easier by traders, because traders do not need to weigh the bananas they sell and this strategy or method has long been used by banana traders in traditional markets.

\section{PENDAHULUAN}

Pasar merupakan suatu wadah bagi masyarakat untuk melakukan aktivitas ekonomi dan mencari kebutuhan sehari-hari. Berbagai macam kebutuhan yang kita perlukan dapat kita temukan di pasar. Mulai dari kebutuhan primer (pokok), 
kebutuhan sekunder (tambahan), hingga kebutuhan tersier (mewah). Aktivitas ekononomi dalam pasar dibuktikan dengan adanya kegiatan transaksi jual beli yang terjadi antara pedagang dan pembeli di dalam pasar. Pasar secara umum diartikan sebagai tempat penjual menawarkan barang atau jasa sesuai taksiran harga penjual, serta pembeli mendapatkan barang atau jasa sesuai dengan taksiran harga pembeli. Pengertian pasar dalam ilmu ekonomi lebih konseptual, yakni pasar tidaklah selalu berupa tempat nyata bertemunya penjual dan pembeli tetapi pasar merupakan suatu transaski tawar menawar suatu barang atau jasa (Widaningsih dan Ariyanti, 2018:12).

Pasar menurut tata cara transaksinya dibedakan menjadi dua macam yaitu pasar modern dan pasar tradisional. Pasar modern adalah pasar yang dikelola secara modern dengan berbagai fasilitas modern (Widaningsih dan Ariyanti, 2018:12). Contoh pasar modern yaitu seperti supermarket, mall, mini market, shopping centre, departemen store dan sebagainya. Sedangkan pengertian pasar tradisional menurut peraturan presiden nomor 112 tahun 2007 adalah pasar yang dibangun dan dikelola oleh pemerintah pusat, pemerintah daerah, BUMN, BUMD, dan pihak swasta yang tempat usahanya berupa kios-kios di dalam pasar dan apabila bertransaksi penjual dan pembeli bertemu secara langsung di kios penjual.

Penentuan harga jual kerap kali menjadi masalah yang sering dihadapi oleh para pelaku usaha pada proses tawar menawar dalam menjual ataupun memasarkan produknya. Menurut Kasmir (2007:175), Harga, price, cost atau value adalah jumlah uang yang harus dibayar oleh pelanggan untuk memperoleh suatu produk. Pada prinsipnya harga jual merupakan harga yang ditentukan sebesar biaya-biaya yang dikeluarkan ditambah dengan laba yang diharapkan. Harga jual sama dengan biaya produksi ditambah mark-up, (Mulyadi, 2012:78). Menurut Mulyadi (2010:9), Biaya merupakan pengorbanan sumber ekonomi yang diukur dalam satuan uang, yang telah terjadi atau yang kemungkinan akan terjadi untuk tujuan tertentu. Biaya merupakan jenis penggunaan dana untuk pembiayaan kegiatan rutin (expense) maupun kegiatan non-rutin (losses), (Warsono, 2009:26).

Keputusan dalam penentuan harga jual sangatlah penting sifatnya, karena selain mempengaruhi laba yang ingin dicapai, penentuan harga jual juga akan 
Endah Masrunik, Bambang Septiawan dan Anditya Dian / Akuntabilitas 12 (2) 2019, 97-105

mempengaruhi kelangsungan hidup suatu usaha. Selain itu penentuan harga jual juga akan mempengaruhi citra suatu produk di mata konsumen. Oleh karena itu dalam menentukan harga jual produk haruslah dilakukan dengan menggunakan strategi dan perhitungan yang tepat agar tidak menimbulkan kerugian dalam kegiatan usaha.

Di dalam ilmu ekonomi terdapat beberapa metode yang dapat digunakan untuk menghitung ataupun menentukan harga jual, Menurut Badri, dkk (2012:63) terdapat empat metode dalam penetapan harga jual, yaitu:

1) Metode Penetapan Harga Biaya-Plus

Merupakan metode penentuan harga jual perunit dengan menghitung seluruh biaya yang terjadi untuk setiap unit barang atau jasa ditambah dengan laba yang di harapkan, adapun rumusnya: Harga jual= Biaya Total + Marjin.

2) Metode Penetapan Harga Mark-Up

Adalah variasi lain dari metode cost plus. Metode ini diterapkan untuk pembelian barang yang langsung di jual kembali tanpa memerlukan proses produksi. Metode mark up ini banyak dipakai oleh pedagang perantara. Adapun rumus perhitungannya sebagai berikut: Harga Jual = Harga Beli + Mark Up.

3) Metode Target Pricing

Pada metode ini harga ditetapkan berdasarkan tingkat pengembalian investasi $(\mathrm{ROI})$ yang diinginkan, Rumusnya yaitu: Harga Sasaran $=($ Biaya per Unit+Tingkat Pengembalian yang Diinginkan+Modal yang Diinvestasikan) : (Unit Penjualan)

4) Metode Pasar atau Pesaing

Harga jual produk ditetapkan berdasarkan harga produk pesaing. Tidak berdasarkan unsur biaya, hargalah yang menentukan biaya produk. Dengan metode ini, harga jual produk dapat ditetapkan berdasarkan tiga alternatif yaitu: 1) Sama dengan harga produk pesaing, atau 2) Lebih rendah daripada harga produk pesaing, atau 3) Lebih tinggi daripada harga produk pesaing. 


\section{METODE PENELITIAN}

\section{Jenis Penelitian}

Jenis penelitian yang digunakan dalam penelitian ini adalah penelitian kualitatif. Penelitian kualitatif adalah pengumpulan data pada suatu latar alamiah dengan maksud penafsiran terhadap suatu fenomena atau aktivitas yang terjadi, peneliti berperan sebagai instrument kunci, proses pengambilan sampel sumber data dilaksanakan secara purposive dan snowball, teknik pengumpulan dengan trianggulasi (gabungan), analisis data bersifat induktif/kualitatif dan hasil penelitian kualitatif lebih menekankan makna dari generalisasi, (Anggito dan Setiawan, 2018:8)

\section{Pendekatan Fenomenologi}

Menurut Husserl dalam Moleong (2014:14), fenomenologi diartikan sebagai: 1. Pengalaman subjektif atau pengalaman fenomenologikal, 2. Studi tentang pandanganatau pemikiran seseorang. Istilah fenomenologi sering digunakan sebagai anggapan umum suatu sudut pandang, pemikiran dan pengalaman yang di alami oleh subjek penelitian. Sehingga fenomenologi merupakan suatu penelitian tentang pengalaman maupun sudut pandang, tingkah laku yang fenomenal dari seseorang.

Menurut Biklen dalam Moleong (2009:248), Analisis data kualitatif merupakan suatu upaya yang dilakukan dalam suatu penelitian dengan cara bekerja dengan data, mengorganisasikan data, memilah milah data sehingga menjadi satuan yang dapat dikelola, memadukan data, mencari dan menemukan pola, untuk menemukan apa yang dapat disampaikan kepada orang lain.

\section{Tehknik Pengumpulan data}

Pengumpulan data dalam penelitian ini di lakukan dengan cara: 1). observasi, dimana peneliti terlibat secara langsung dan mengamati, sikap tingkah laku dan kegiatan-kegiata yang dilakukan subjek penelitian (Prastowo, 2011:220). 2). Wawancara, merupakan suatu tindakan Tanya jawab yang dilakukan peneliti kepada subjek penelitian. 3). Dokumentasi, semua yang dapat digunakan untuk mengambil informasi yang dibutuhkan peneliti (anggito dan setiawan, 2018:146).

\section{PEMBAHASAN}

Pasar Kesamben, Pasar Wlingi dan Pasar pon Blitar merupakan pasar tradisional di Kabupaten dan Kota Blitar. Beberapa pasar tersebut merupakan pusat perdagangan pisang terbesar di kabupaten dan kota Blitar. Banyak pedagang dari Strategi Lirang Dalam Penentuan Harga Jual Pisang Dalam Pasar Tradisional Blitar. 
Endah Masrunik, Bambang Septiawan dan Anditya Dian / Akuntabilitas 12 (2) 2019,97-105 pasar lain yang datang untuk membeli pisang di dalam pasar Kesamben, Pasar Wlingi, maupun pasar pon blitar. Buah pisang yang diperdagangkan di pasar tersebut merupakan buah pisang asli dari wilayah Blitar yang di dapat dari mitra kerja pedagang.

Mitra kerja akan mengantarkan langsung pisang yang diperdagangkannya ke kios pedagang pisang. Selain itu terkadang pedagang juga keliling menggunakan sepedah motor ke petani-petani buah pisang untuk mendapatkan buah pisang yang diperdagangkannya.

Dalam proses pembeliannya setiap buah pisang mempunyai harga beli yang berbeda-beda. Buah pisang dibeli pedagang dalam satuan tundhun, dan setiap tundhun pisang memiliki harga yang berbeda. Dalam hal ini terdapat beberapa faktor yang menjadi pembeda harga beli pada buah pisang yang diantarannya yaitu jenis buah pisang, ukuran, banyaknya lirang dalam satu tundhun, kondisi pasar saat itu dan status penjual (langganan atau bukan). Maka dari itu, diperlukan kecermatan dari pedagang dalam membeli buah pisang yang akan diperdagangkannya.

Buah pisang yang dijual di pasar-pasar tersebut beragam jenisnya, diantaranya yaitu pisang ambon, pisang kepok, pisang susu, pisang raja, pisang cnadi, pisang barlin, pisang raja nangka, pisang raja santen, pisang emas, pisang tanduk dan maasih banyak lagi. Dan dari tiap jenis pisang mempunyai harga yang berbedabeda. Sehingga dengan beragamnya jenis pisang dan banyaknya pedagang memunculkan persaingan antar pedagang. Dalam mengatasi persaingan tentu para pedagang dituntut untuk memiliki strategi yang baik. Strategi ini bermacam-macam bentuknya, salah satunya yaitu strategi dalam menentukan harga jual. Harga jual sama dengan biaya produksi ditambah mark-up, (Mulyadi, 2012:78).

Dalam menentukan harga jual pedagang belum menggunakan metode perhitungan yang pasti. Hal ini disebabkan karena kurang baiknya atau bahkan tidak adanya proses (pencatatan) akuntansi yang dilakukan oleh para pelaku usaha (pedagang). Pernyatan ini sesuai dengan penelitian Ikawati (2018) bahwa dengan tidak adanya pencatatan akuntansi maka tidak dapat mengidentifikasi biaya-biaya yang timbul dalam kegiatan usahanya. Selama ini pedagang menetapkan harga jual dan laba hanya berdasarkan perkiraan/estimasi tanpa melalui perhitungan yang 
sesuai dengan metode akuntansi. Hal ini sesuai dengan penelitian Woran, IIat dan mawikere (2014) bahwa penetapan harga jual yang tanpa melalui perhitungan sesuai kaidah akuntansi maka perhitungan harga jual ditetapkan berdasarka perkiraan/estimisasi. Pedagang buah pisang menentukan harga jual berdasarkan sisir atau lirang pisang dan laba yang diinginkan berdasarkan perkiraan saja tanpa memperhitungkan biaya-biaya yang dikerluarkan pedagang selama proses penjualan. Hal ini dijelaskan oleh Ibu Wijiatun selaku pedagang di pasar Pon Blitar, yang disajikan dalam kutipan wawancara sebagai berikut:

“aku adole gedhang perlirang mas, yo kadang enek sing tuku sak tundhun tapi kuwi jarang, akeh-akeh tukune perlirang, lha regone gedhang kuwi bedo-bedo mben lirange, delok-delok jenis gedhange, akeh opo orane cah-cah e gedhang sak lirange, terus gedi cilike gedhang, karo ndelok-ndelok pembeline ki wani opo gak, dadi aku lek matok harga yo tak kiro-kiro ben gak terlalu dhuwur mergane kan pembeli ki enek sing wani enek sing enggak, dadi matokku rego yo pokok sekirane bathi ngono yo tak dol". [kalau aku jualnya ngecer mas, jadi jualnya berdasarkan lirang, ya kadang ada yang beli satu tandan tapi itu jarang, yang banyak orang belinya persisir, lha harga pisang itu berbeda-beda tiap jenis pisangnya, lihatlihat jenis pisangnya, banyak tidaknya buah pisang dalam satu lirangnya, terus besar kecilnya pisang, sama liat pembeli itu berani apa enggak, jadi saya kalau menentukan harga itu ya saya kira-kira biar harganya gak terlalu tinggi karena kan pembeli itu ada yang berani ada yang tidak, jadi saya menentukan harga ya pokok sekiranya untung begitu ya saya jual].

Dari hasil wawancara dengn ibu Wijiatun menunjukkan tentang penetapan harga jual secara lirang dengan melihat karakteristik tiap lirang yaitu: jenis pisang yang diperjualbelikan, jumlah pisang dalam tiap lirang, besar/kecilnya pisang dalam tiap lirang, tingkat keatangan dan harga pasar.

Hal tersebut tidak jauh berbeda dengan yang diungkapkan oleh Bapak Slamet selaku pedagang pisang pasar kesamben sebagai berikut:

"aku adole kadang yo pertundhun kadang yo ngecer, tapi sing kerep yo adole ngecer perlirang ngono kae, lek adole pertundhun kuwi standar e aku njupuk bathi sekitar sepuluh ewu sampek limolas ewu, tha lek ngecer kuwi standar e jupuk ku bathi sekitar telung puluh ewu sampek patang puluh ewu pertundhun e, dadi bathine rodok akeh lek di dol ngecer mas,". [saya jualnya kadang ya pertandhan kadang ya ngecer, tapi yang sering jualnya ngecer perlirang gitu, kalau jualnya pertandhan gitu standarnya saya mengambil untung 

sekitar Rp.10.000 sampai Rp.20.000, lha kalau ngecer itu saya mengambil untung sekitar Rp.30.000 sampai Rp.40.000, jadi keuntungannya agak banyak kalau dijual ngecer].

Pernyataan Bapak Slamet menunjukakan bahwa penjualan pisang biasa dilakukan perthandhan maupun perlirang. Namun laba yang di hasilkan akan lebih banyak jika pisang dijual secara lirang.

Hal serupa juga diungkapkan oleh Bapak Nurkarim selaku pedagang di pasar wlingi sebagai berikut:

"ndelok harga tukune, gedange tak lirangi. Sak thundhun enek pirang lirang. Trus dikiro-kiro pengen njupuk bathi piro saktundhun ne. ben lirang regane ndak podho. Biasane lirangan dhuwur dewe regane sing larang dewe. Mergo gedhange apik-apik lan gedhi-ghedi cacahe gedhang yo okeh dewhe (lihat harga belinya, pisang satu thandhan dibagi-bagi menjadi beberapa lirang. Tiap lirang harganya berbeda. Biasanya lirang pisang yang paling atas harganya yang paling mahal karena pisangnya bagus-bagus dan besar-besar serta jumlah buah pisang banyak sendiri)"

Hasil wawancara dengan Bapak Nurkarim menjelaskan bahwa penjualan secara lirang dilakukan dengan melihat harga beli serta kualitas pisang. Kualitas pisang yang bagus harga jualnya akan lebih tinggi dari pada kualitas pisang yang kurang bagus.

Pernyataat tersebut sedikit berbeda dengan penelitian Khairiyah (2017) yang menyatakan bahwa penetapan harga jual selain melihat modal, kualitas buah, dan harga bersaing juga melihat klasifikasi konsumen. Dimana penetapan harga jual akan berbeda pada setiap pembeli dengan penampilan yang berbeda.

Dari beberapa pernyataan pedagang tersebut dapat diketahui bahwa strategi penjualan pisang menggunakan strategi lirang. Dengan strategi lirang penjualan dapat meraih keuntungan yang lebih besar dari pada penjualan secara thandhan. Harga jual yang ditetapkan antar pedagang juga berbeda-beda karena hanya melihat harga beli dan menambah laba yang diingikan pada tiap lirang pisang. Namun perbedaan harga ini tidak terlalu signifikan. 
Hal ini selaras dengan penelitian Putri dan Isdianto (2018:5) yang menyatakan bahwa penetapan harga jual dengan hanya melihat harga beli tidak memberikan berpedaan harga yang signifikan apabila di jual secara ecer.

Laba yang ditentukan pedagang berkisar Rp.30.000 - Rp.40.000, bahkan juga bisa lebih untuk setiap tundhun pisang yang telah diecer menjadi satuan lirang. Laba tersebut merupakan laba standar yang ditentukan oleh para pedagang buah pisang. Dan harga jual maupun laba yang ditentukan tersebut dapat berubah-ubah tergantung kondisi pasar pada saat itu. Sehingga apabila pedagang membeli buah pisang dengan harga Rp.50.000,- maka akan terjual dengan harga sekitar Rp.60.000,sampai Rp.700.000,- apabila di jual perthandhan, namun pisang tersebut akan terjual dengan harga Rp.80.000,- sampai Rp.90.000,-- apabila dijual dengan lirangan.

Strategi penjualan pisang dengan satuan lirang ini sudah sejak dulu dan sudah turun menurun digunakan pedagang buah pisang dalam menentukan harga jual buah pisang. Dan cara ini dinilai pedagang mudah penerapannya karena pedagang juga tidak perlu menimbang bobot buah pisang yang dijual. Namun dalam hal ini pedagang buah pisang harus mempunyai perkiraan yang tepat dalam menentukan harga jual buah pisang agar buah pisang dapat laku terjual.

\section{KESIMPULAN}

Strategi yang digunakan pedagang buah pisang Pasar tradisional Blitar sebagai dasar dalam menentukan harga jual pisang yaitu strategi lirang/sisir pisang. Pedagang buah pisang Pasar tradisional Blitar dalam menentukan harga jual dengan membagi thandhan pisang menjadi beberapa lirang dan melihat jenisnya, ukuran, jumlah buah pisang dalam satu lirang, tingkat kemasakan, dan kondisi pasar saat itu. Harga ditentukan dengan menambahkan harga beli dengan laba yang diinginkan untuk tiap lirangnya. Penentuan laba ini hanya didasarkan pada perkiraan pedagang saja tanpa memperhitungkan beban atau pun biaya yang mereka keluarkan dalam kegiatan usahanya. Laba yang ditentukan pedagang dalam berdagang buah pisang mencapai Rp.30.000 - Rp.40.000, bahkan juga bisa lebih untuk setiap tundhun pisang yang telah diecer menjadi satuan lirang. Laba tersebut merupakan laba standar yang ditentukan oleh para pedagang buah pisang. Sehingga harga jual yang ditetapkan berubah-ubah dan tidak sama antar tiap pedagang. 


\section{DAFTAR PUSTAKA}

Anggito, Albi dan Setiawan Johan, 2018. Metode Penelitian Kualitatif. Sukabumi: CV Jejak.

Badri, Muhammad Arifin, dkk. 2012, Majalah Pengusaha Muslim: Jangan Menyuap. Penerbit: Yayasan Bina Pengusaha Muslim.

Ikawati, Akbriana Diyah. 2016. Penetapan Harga Jual Dengan Metode Cost Plus Pricing Pada Warung Sederhana 2 Jetis Kulon Surabaya.

J. Moleong, Lexy. 2014. Metode Penelitian Kualitatif Edisi Revisi. Bandung: PT. Remaja Rosdakarya.

Kasmir. 2007. Kewirausahaan. Jakarta: PT. Rajawali Pers.

Khairiyah, salehatul. 2017. Penetapan Harga Buah Berdasarkan Klasifikasi Konsumen Menurut Etika Bisnis Islam (Studi Pada Pedagang Buah di Kecamatan Sebangau Kota Palangka raya). Skripsi:Institut Agama Islam Negeri Palangkaraya

Mulyadi. 2012. Akuntansi Biaya Edisi kelima cetakan kesebelas. Yogyakarta: Penerbit UPP STIM YKPN.

Prastowo, Andi. 2011. Metode Penelitian Kualitatif Dalam Perspektif Rancangan Penelitian. Yogyakarta: Ar-Ruzz Media.

Putri, Rika Dianing dan Isdianto. 2018. Penetapan Harga Jual Buah Jeruk Oleh pdeagang Pengecer (Studi Ksus Pada Pedagang Pengecer Buah Di Kawasan Kota Sumenep). Cemara,vol.15, no. 1

Republik Indonesia. 2007. Peraturan Presiden Nomor 112 Tahun 2007 Tentang Penataan Dan Pembinaan Pasar Tradisional Pusat Perbelanjaan Dan Toko Modern. Sekretariat Kabinet RI. Jakarta.

Warsono, Darmawan dan Ridha. 2009, Akuntansi Itu Ternyata Logis dan Mudah. Yogyakarta: Asgard Chapter

Widaningsih dan Ariyanti. 2018. Aspek Hukum Kewirausahaan. Malang: Penerbit Polinema Press.

Woran, Reza. Ventje llat dan lidia Mawikere. 2014. Penentuan Harga Jual Produk Dengan Menggunakan Metode Cost Plust Pricing Pada Ud. Vanela. Jurnal Emba: Jurnal Riset Ekonomi, Manajemen, Bisnis Dan Akuntansi 2(2). 